\title{
Framework Structure on Personnel Training Mode for Tourism Management Major of Middle Vocational Undergraduate
}

\author{
Hongyan Liu \\ College of Finance and Trade, Bohai University, Jinzhou, 121013, China
}

47203209@qq.com

\begin{abstract}
Keywords: middle vocational undergraduate; tourism management major; personnel training mode; framework structure
\end{abstract}

\begin{abstract}
Vigorous development of the tourism industry provides new opportunities for the construction of Tourism Management Specialty in Colleges and universities. This paper is aimed at the problems in the cultivation of the middle vocational undergraduate tourism management major personnel training mode, to improve the quality of personnel training services. With the characteristics of the students in secondary vocational college, based on the goal of personnel cultivation and social needs, the seven framework structure is built, which is a positioning, two systems, three training, four module, five flat, six kinds of knowledge and nine skills. The successful application of the research results of this paper is of great significance in improving students' quality, innovative training methods, strengthening students' ability and adapting to social development.
\end{abstract}

\section{Introduction}

Tourism management major is a new discipline with the development of China's tourism economy and the development of tourism industry. In China, the subject of this discipline is only twenty years, but becomes an important branch of the management discipline system. Tourism management has been tied to business administration, it is a discipline of management science. The students mainly study the basic theory and knowledge of modern management science, which is trained and trained by the general management method, the basic quality and the basic ability of management personnel, and master the modern management theory, technology and methods, and have the basic ability of planning, coordination, organization and decision-making [1].

"Personnel training mode" refers to the sum of the teaching contents and curriculum system, the management system and the evaluation method, and the process of implementing the personnel education in the teaching content and the curriculum system, the management system and the curriculum system. With the deepening of the reform of education system and the development of social education demand, since 1980s, the problem of personnel training mode has gradually become an important issue of higher education in China. Today, however, the reform and innovation of personnel training mode is still the weak link in the development of higher education.

With China's accession to the world trade organization, the tourism industry will be developed rapidly, the market will continue to improve, the need for a large number of new professional talents to adapt to the development of market economy and domestic and international tourism. For a long time, the undergraduate education of Tourism Management in China has formed a system of educational teaching mode, which is based on the knowledge of the system, the subject knowledge production as the goal, the subject knowledge as the tool, the heavy subject knowledge system, the light society need to beg. However, the social needs to the service economy and social construction of the personnel, the personnel of professional knowledge, practical skills, professional quality, job adaptability and resilience requirements. Especially in the secondary vocational college students, the theory foundation is poor, but also not to adapt to the ordinary undergraduate training mode. This paper is aimed at the characteristics of the students in the middle vocational undergraduate school, with the demand of tourism management professional talents as the guide, the research personnel training mode framework structure, in order to improve the quality of service. 


\section{Making Process of Personnel Training Mode}

Personnel training mode can not only be limited in the teaching process, but also can not be generalized to the whole management level of colleges and universities, is a static style and dynamic mechanism of unity. Because the personnel training mode is not only related to the teaching process, but also the process of education, which involves the whole process of education, far beyond the scope of teaching. Personnel training mode develops process as shown in Fig. 1.

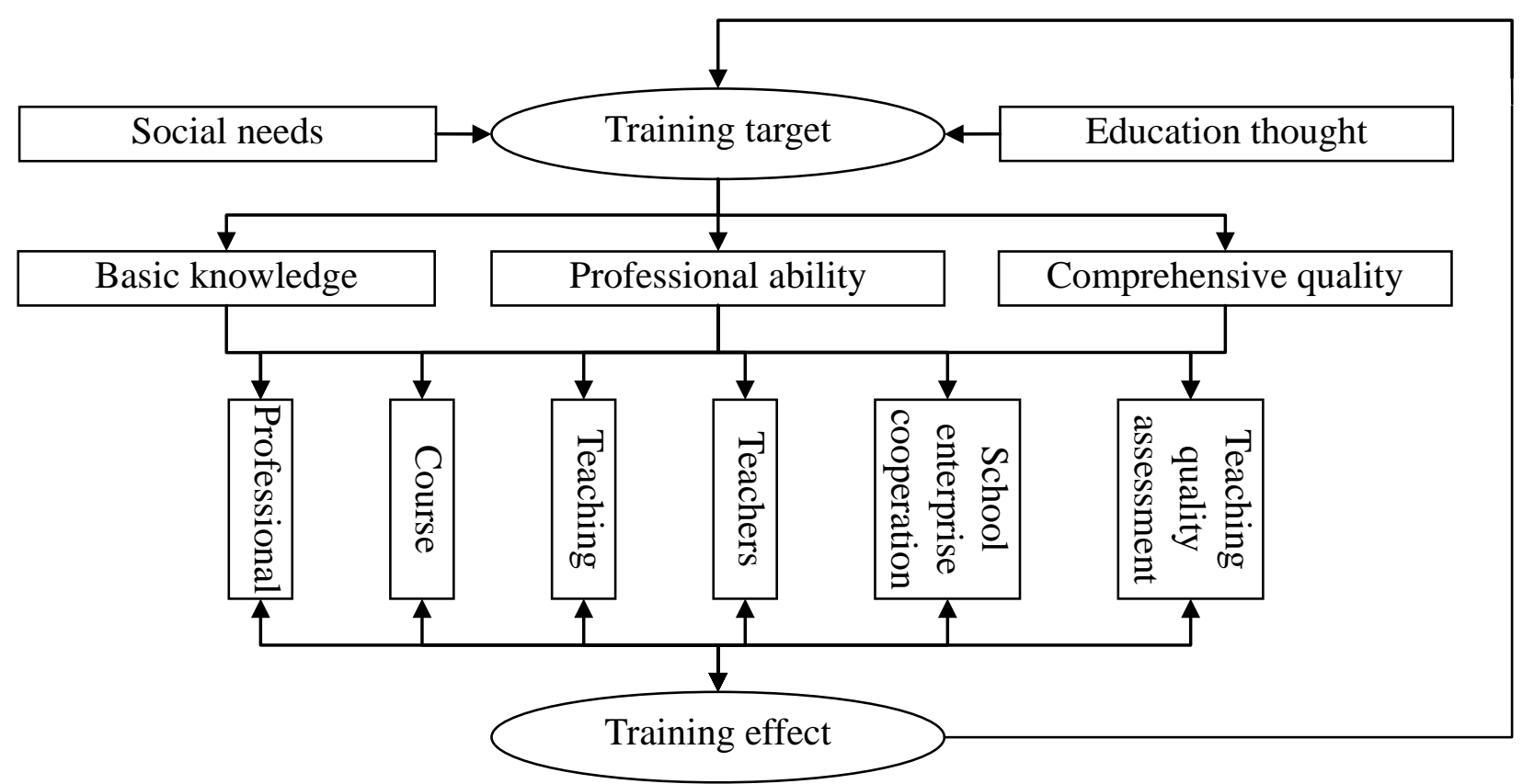

Fig. 1. Making process on personnel training mode

Personnel training mode is the core of training objectives, social needs and education ideas as the guide, from the basic knowledge, professional ability and comprehensive quality and other three aspects, including" professional, course, teaching, teachers, school enterprise cooperation, teaching quality assessment" etc. According to the training mode, we can make the local adjustment of "professional, course, teaching, teachers, school enterprise cooperation, teaching quality assessment", and also can be reset to develop the training model. Among them, meeting the needs of society is the ultimate goal of personnel training, the personnel demand of tourism management specialty is various, including the application oriented, entrepreneurial and international, the quality of talents, including the good psychological quality, the ability of language use, intercultural communication ability and innovation ability. It is helpful for people to grasp the reality of education, and to make people based on a certain educational thought in education practice. It helps people recognize the achievements and shortcomings of the education work, and make the education work better. It can be helpful for people to predict the future, outline the blueprint of education development, the training objective of Tourism Management major in vocational college can be summed up [3], cultivate the basic line, moral, intellectual, physical, aesthetic and other comprehensive development, meet the needs of local tourism development, has the modern tourism management and means, and has strong practical ability, strain capacity and certain innovation ability, and can be used in the management and service work. 


\section{Framework Structure of Personnel Training Mode}

The framework structure of the personnel training mode of tourism management major in the middle vocational undergraduate school is shown in Fig. 2. Framework structure composed of 7 layers, from bottom peaked respectively is: a position, two systems, three training, four modules, five platforms, six knowledge, nine abilities.

First layer: a position, the vocational undergraduate students is a special group, junior high school when the majority of performance, and therefore the choice of secondary vocational and technical schools. Most of the students' learning enthusiasm is not high, lack of motivation, lack of positive learning motivation, learning foundation is poor. But this has caused the student intelligence quality is not bad, the thought is agile, the practical ability is strong, to the new thing, the new idea is easy to accept, the adaptability is strong. Aiming at these characteristics, combined with the training objectives of tourism management, a position of personnel training is to "engage in the management and service of the application of advanced professional personnel".

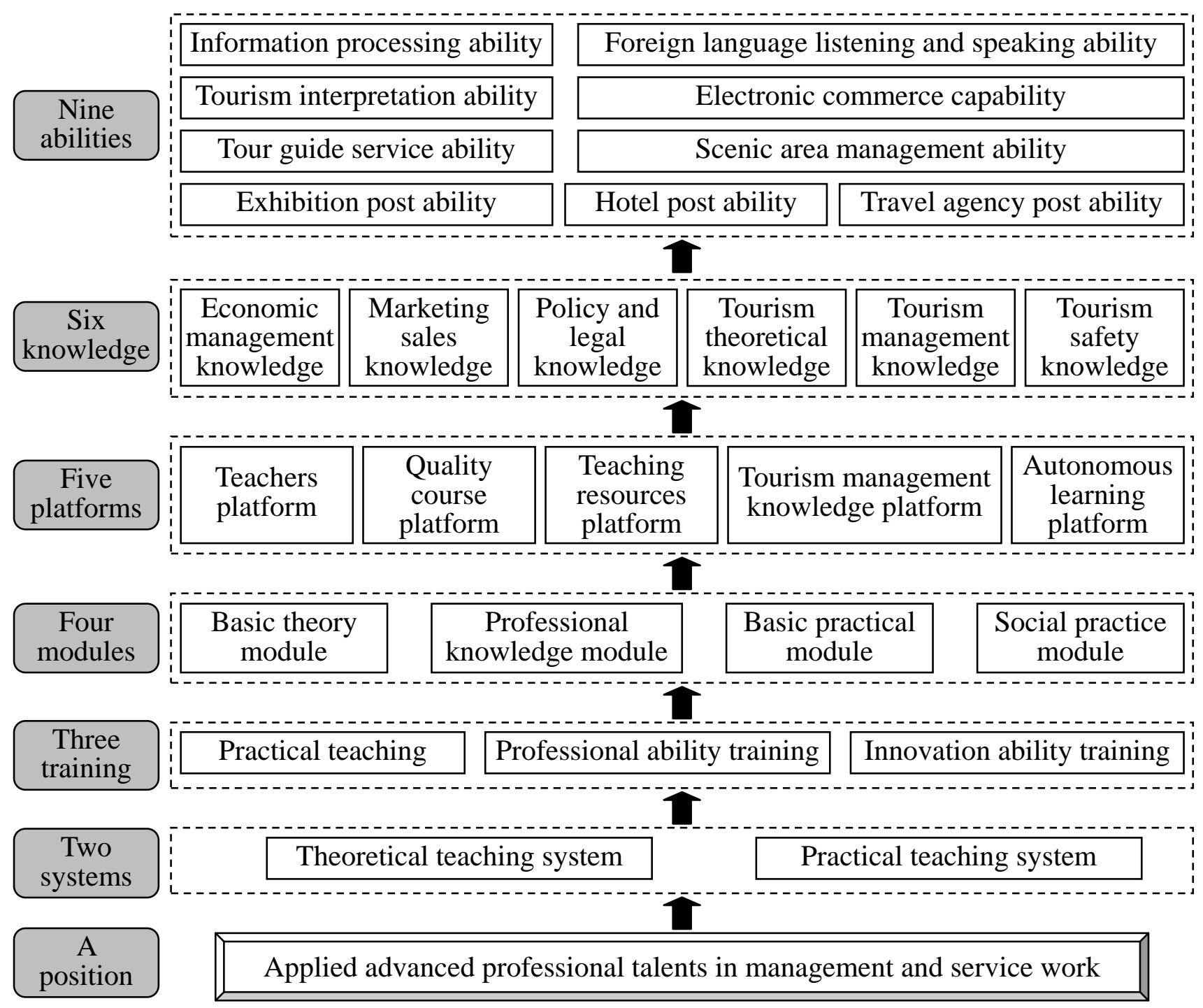

Fig. 2. Framework structure of personnel training mode

Second layer: two systems, Theory teaching system and practice teaching system. Theoretical teaching can make the students master the concept system of discipline, cultivate the ability of rational thinking [4]. Through theoretical teaching, the academic performance is demonstrated, and the theoretical innovation is encouraged, especially the important theoretical innovation. Practical teaching system is an organic whole, which is composed of various elements of practical teaching activities, and is the main way to cultivate students' practical ability. Not only to provide a clear 
idea of the teaching, but also to provide a strong guarantee for the training of applied talents. The combination of theory and practice should be carried through the teaching activity. Teaching emphasis on the theory of "knowledge". Practice teaching more emphasis on the cultivation of "skills".

Third layer: three training, The practical teaching, training professional ability and innovation ability. Tourism management major has the characteristics of practicality, it is necessary to improve the students' practical ability. Through strengthening practical teaching, on the one hand, make discipline problems, social life and situation, on the other hand, students actively participate in social practice and life practice, the tourism management major knowledge can have a more thorough understanding [5]; Through enhancing the professional ability training, promote communication ability, master the basic norms of life and workplace etiquette and cultivate team cooperation ability, improve competitiveness, be able to deal with the problem with strong ability of coordination and strain; Through enhancing the innovation ability training, foster the students' innovation consciousness, innovation spirit and innovation ability, make its become creative talents, this is the age and society for education in the new period of work put forward higher requirements, is to meet the era of knowledge economy demands for high-quality talents important way and effective measure, also is the direction of the development of higher education, teaching reform, tide and trend.

Fourth layer: four modules, That is, basic theory, professional knowledge, basic practice and social practice. The basic theory module is completed by discipline basic courses, including management principles, management information system, management psychology, marketing, economics, accounting, statistics, western economics, labor economics, organizational behavior, etc., and professional knowledge module is completed through specialized courses, including tourism, tourism geography, tourism economics, tourism policies and regulations, hotel management, tourism culture, professional manager theory and practice.

Fifth layer: five platforms, That is, the platform of teachers, quality course, teaching resources, tourism management platform and autonomous learning platform. The teaching platform by professional teachers, teachers are the implementer of the purpose of education, the teaching activities of the designers, to promote the education development and education to achieve the purpose of the platform [6]; excellent course by course related resources, curriculum is a first-class teachers, first-class teaching content, teaching methods, first-class teaching materials, first-class teaching management etc. the characteristics of the model curriculum; teaching resources platform is to provide teaching materials and can be used, including textbooks, case, video, pictures, courseware, teaching aids, such as infrastructure; knowledge platform of Tourism Management for tourism information provide students with teaching content, expand students' knowledge of tourism; autonomous learning platform based on knowledge point as the center, the ability to test for means, to provide network learning platform to set the teaching and learning, training, examination, evaluation and other functions in one of the students, by means of the network can learn whenever and wherever possible.

Sixth layer: six knowledge, Knowledge of economic management, marketing, policy and law, tourism, tourism management and tourism safety. Knowledge economy and management, tourism management major is tourism science, management science, economics, culture and cross integrated professional, economic and management knowledge is an essential knowledge base; marketing knowledge, research in supply and demand of tourism market, tourism to meet the consumers as the center, the development of marketable tourism products, to achieve the maximum of social the economic benefits of knowledge; knowledge of laws, regulations and policy based tourism knowledge, practical problems to analyze and solve the tourist reception, to the various problems and accident prevention in tourism, improve the strain capacity; tourism theory, tourism is the corresponding professional post group theoretical knowledge is needed, abstract the high degree of generality, tourism knowledge system, tourism management, tourism human resources management, tourism culture, tourism psychology, tourism public relations and other aspects of 
knowledge, tourism safety knowledge, tourism safety knowledge, tourism activities in all the relevant subject of all safety knowledge, including tourism activities related phenomena.

Seventh layer: nine abilities, Nine abilities, namely the ability of information processing, foreign language listening and speaking, electronic commerce, tourism interpretation ability, the ability to guide service, travel agency post ability, hotel post ability, the ability to manage the area, exhibition position. Information processing ability, which has the ability of acquiring, processing and applying information, through computer culture, computer basic course, and foreign language listening and speaking ability, the ability to communicate in English, tourism English and other courses; In tourism interpretation ability, guide the tourists to visit, the use of oral expression ability of explanation to people, objects, scene, through the tourism interpretation system, tourism interpretation and road show course; tour guide service ability is the basic ability, worked as a tour guide should have, including the ability to explain, standardize the service ability, special problems and the ability to achieve, through the guide of basic knowledge, tourism service standard courses; travel agency post ability, ability of organization, management, management of travel agency, through travel agency management, tour route design courses; hotel post ability, ability of organization, management, management of the hotel, the through the catering operation management, lobby room management courses; Scenic management capabilities, rational organization of human, material and financial resources to achieve the objectives of the management process, through the management of tourist attractions, tourism traffic management, tourism planning and development, and other courses to achieve the ability to engage in planning, assessment, planning and monitoring, financing, procurement, contract and other aspects of management knowledge, through the exhibition planning and creative, exhibition management and other courses.

\section{Conclusion}

The vigorous development of the tourism management major provides new opportunities for the construction of Tourism Management Major in Colleges and universities. With the continuous deepening of the reform of China's education, middle vocational undergraduate enrollment increased year by year. To meet the needs of the market, to personal training mode, to make clear the personal training objectives, to develop the middle vocation undergraduate, to meet the challenges and to get rid of the predicament of professional development [7]. The research content of this paper is to solve the core problem of the reform of the training mode of Tourism Management Major in the secondary vocational college, which has important significance for improving students' quality, innovative training methods, strengthening students' ability and adapting to social development.

\section{References}

[1] Fresh graduates - Career Planning, "Analysis of employment prospects of tourism management major in 2015," http://zhiyeguihua.yjbys.com/jiuyeqianjing/259899.html, 2015-10-4.

[2] D. Y. Meng, F. Zhao, "The training mode of the modern apprentice system in higher vocational tourism management specialty in China," Education and Vocation, vol. 99, no. 2, pp. 117-118, 2015.

[3] D. Y. Zheng, "Research on the Training Target and Orientation of Tourism Management Specialty in Higher Vocational Colleges," Heilongjiang Researches on Higher Education, vol. 27, no. 4, pp. 97-98, 2008.

[4] X. Y. Ren, "Integrated model of theory teaching and practice teaching in application oriented personnel training," Knowledge Economy, vol. 16, no. 23, pp. 147, 2014.

[5] W. C. Xiao, "Exploring and Implementing of the Integration Mode of Theory and Practice Teaching," Research and Exploration in Laboratory, vol. 30, no. 4, pp. 81-85, 2011. 
[6] F. Q. Wang, "Characteristics, problems and countermeasures of the training mode of tourism management major in vocational colleges in Inner Mongolia," Journal of Inner Mongolia Normal University(Educational Science), vol. 28, no. 3, pp. 34-37, 2015.

[7] D. Y. Zhang, "Research on the Application and Innovation - oriented Talents Training Mode of Tourism Management Majors at Colleges and Universities," Academic Exploration, vol. 23, no. 2, pp. 73-77, 2015. 